\title{
Removal Techniques for Intracanal Medicament- A Review
}

\author{
Samrudhi Sunil Khatod ${ }^{1}$, Anuja Dhananjay Ikhar², Pradnya Prashant Nikhade ${ }^{3}$, Manoj Chandak ${ }^{4}$, \\ Nidhi Manohar Motwani ${ }^{5}$, Madhulika Shyamsundarji Chandak ${ }^{6}$, Chanchal Kishor Rathi ${ }^{7}$, Arpan Sanjay Jaiswal ${ }^{8}$
}

\begin{abstract}
${ }^{1}$ Department of Conservative Dentistry and Endodontics, Datta Meghe Institute of Medical Sciences, Sharad Pawar Dental College, Sawangi, Wardha, Maharashtra, India. ${ }^{2}$ Department of Conservative Dentistry and Endodontics, Datta Meghe Institute of Medical Sciences, Sharad Pawar Dental College, Sawangi, Wardha, Maharashtra, India. ${ }^{3}$ Department of Conservative Dentistry and Endodontics, Datta Meghe Institute of Medical Sciences, Sharad Pawar Dental College, Sawangi, Wardha, Maharashtra, India. ${ }^{4}$ Department of Conservative Dentistry and Endodontics, Datta Meghe Institute of Medical Sciences Sharad Pawar Dental College, Sawangi, Wardha, Maharashtra, India. ${ }^{5}$ Department of Conservative Dentistry and Endodontics, Datta Meghe Institute of Medical Sciences, Sharad Pawar Dental College, Sawangi, Wardha, Maharashtra, India. ${ }^{6}$ Department of Conservative Dentistry and Endodontics, Datta Meghe Institute of Medical Sciences, Sharad Pawar Dental College, Sawangi, Wardha, Maharashtra, India. ${ }^{7}$ Department of Conservative Dentistry and Endodontics, Datta Meghe Institute of Medical Sciences, Sharad Pawar Dental College, Sawangi, Wardha, Maharashtra, India. ${ }^{8}$ Department of Conservative Dentistry and Endodontics, Datta Meghe Institute of Medical Sciences Sharad Pawar Dental College, Sawangi, Wardha, Maharashtra, India.
\end{abstract}

\section{ABSTRACT}

\section{BACKGROUND}

This article reviews irrigation techniques for removal of intracanal medicament in endodontic practice. Microorganisms are the primary etiological factors for pulpal and periradicular diseases. So primary purpose is to completely eradicate microorganism from the root canal. It is done through chemo-mechanical preparation of the canal. Complete disinfection of the pulp space cannot be achieved with most sophisticated instrumentation techniques. Therefore use of inter appointment intracanal medicaments is mandatory. Removal of the medicament is mandatory, as its remnants may mechanically block the apical area of the root canal system. Also affects viscosity, working time, tubule penetration and adhesion of root canal sealers. Remnants of $\mathrm{Ca}(\mathrm{OH})_{2}$ in the canal react with unreacted eugenol present in ZOE based sealer to form calcium eugenolate. Today's irrigation armamentarium presents a diverse variety of tools and techniques, that can assist the practitioner in reducing bacteria, debris, intracanal medicament within the canal system. Conventional syringe irrigation is a routinely practiced method for removal of medicament. It consists of delivering the irrigant in the canal passively or by agitation. Rotary brush does not actually render irrigating solution for removal of medicament. This acts like auxiliaries during removal of medicament from canal or for increased movement of irrigating solution. Ultrasonic irrigation is done with or without simultaneous ultrasonic instrumentation. EndoVac is negative pressure irrigation, which can be used as an alternative method that helps in safe removal of medicament in apical thirds. RinsEndo is also based on pressure alteration technology like EndoVac. Sonically driven system safely activates various intracanal reagents and vigorously produces the hydrodynamic phenomenon as it includes EndoActivator and Vibringe. Laser activated irrigation is more effective for cleaning of root canal. Er:YAG is most commonly used laser in endodontics. Therefore, the aim of this article is to highlight the irrigation techniques used for removal of the intracanal medicament in endodontic practice.

\section{KEY WORDS}

Calcium Hydroxide, Ultrasonic, Sonic, Manual
Corresponding Author: Samrudhi Khatod, Datta Meghe Institute of Medical Sciences, Radhikabai, F-6, Sawangi-442001, Maharashtra, India.

E-mail: khatod.samrudhi@gmail.com

DOI: $10.14260 / j e m d s / 2020 / 236$

Financial or Other Competing Interests: None.

How to Cite This Article:

Khatod SS, Ikhar AD, Nikhade PP, et al. Removal techniques for intracanal medicament- a review. J. Evolution Med. Dent. Sci. 2020;9(13):1097-1101, DOI: 10.14260/jemds/2020/236

Submission 28-02-2020,

Peer Review 07-03-2020,

Acceptance 12-03-2020,

Published 30-03-2020.

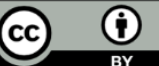




\section{BACKGROUND}

Microorganisms are primary etiological factors for pulpal and periradicular diseases. So primary purpose is to completely eradicate microorganism from the root canal. It is done through chemo-mechanical preparation of the canal. This include proper cleaning and shaping by instrumentation and irrigation. $(1,2,3)$ Because of complexity of root canal, biomechanical preparation fails to completely eradicate microorganism. This left over bacteria might multiply in between appointments and might reach to same previous degree of concentration, so intracanal medicament has been used for complete canal disinfection. Rationale for intracanal medicament use is to totally eradicate microorganism from the root canal and forbid reinfection. $(2,4,5)$

Antimicrobial activity of intracanal medicaments varies, they belong to various groups, mostly different chemicals/drugs are combined to achieve increased efficiency with a single application. Thus, to deactivate microbial activity intracanal medicament with prolonged antimicrobial activity has to be used in between appointments. ${ }^{6,7)}$ Medicament should be efficient during its entire time of application and should penetrate the tubule and eradicate the microbes. Intracanal medicament shows comparatively prolonged antimicrobial action when compared to irrigants.(6) Calcium hydroxide was invented by Herman in 1920 is routinely used intracanal medicament because of its antimicrobial, alkalinity, tissue repair and inhibiting osteoclastic properties. It is used in cases like weeping canal, in blunderbuss canal for apexogenesis and apexification, root resorption cases. ${ }^{(8,9)}$

However prolonged placement of intracanal $\mathrm{Ca}(\mathrm{OH})_{2}$ has adverse effect on dentin, making it prone to root fracture. In many in vitro studies it has been stated that more than 5 weeks of placement of intracanal $\mathrm{Ca}(\mathrm{OH})_{2}$ causes decrease in root fracture resistance. Remnants of $\mathrm{Ca}(\mathrm{OH})_{2}$ in canal react with unreacted eugenol present in ZOE based sealer to form calcium eugenolate. Calcium eugenolate has been observed as disorganized layer which inhibit sealer infiltration in dentin and affects proper seal. Leftover calcium hydroxide get dissolve by tissue fluid and affect apical seal. Also it affect the efficacy of apex locator, bond strength decreases between resin based sealer and dentin when calcium hydroxide was used as intracanal medicament, this might be because of alkalinity of calcium hydroxide which neutralizes acidic monomer present in resin based sealer. Remnants of antibiotic paste is detrimental to stem cells. $(6,10)$

Therefore for thorough removal of medicament especially in apical third use of various irrigation delivery system is essential. Various method employed for removal of smear layer, debris, intracanal medicament are 1) Manual 2) Machine assisted 3) Chemical (irrigants). (11)

\section{MANUAL IRRIGATION}

It comprises of mainly (i) Conventional syringe irrigation (ii) Instrumentation by master apical file or gutta percha.

\section{(i) Conventional Syringe Irrigation}

Routinely practiced method for removal of medicament. Consist of delivering the irrigant in canal passively or by agitation i.e. back and forth motion in canal (2-3 mm strokes). Efficacy depends on gauge of needle and its design, which in turn effect flow, length of infiltration of irrigant, pressure over wall of canal and apical terminus. Penetration depth of needle is inversely proportional to its gauge. 27-gauge needle is favourable for routine root canal treatment.(11)

\begin{tabular}{|cc|}
\hline Needle Gauge & Apex of Size to Which Needle Can Reach \\
21 & ISO size 80 canal \\
23 & Size 50 \\
25 & Size 35 \\
30 & Size 25 \\
\hline & Needle Gauge Selection \\
\hline
\end{tabular}

As per studies it says irrigating solution flow just 1-2 mm away from needle end. Different type of needle tip are invented to enhance efficiency and minimize peril. Openended tips release irrigant from end towards apical region and lead to increase in apical pressure in canal. Closed-ended tips are side-vented therefore to greater extent pressure is on walls of canal and enhance hydrodynamic energizing of irrigant and decrease the chance of apical leakage. Close ended tip causes irrigant to reflux and efficiently displace debris coronally. Advantages of syringe irrigation is control on extent of needle placement in canal and quantity of irrigant to be irrigated in canal. Different sizes of syringe are available from $1-20 \mathrm{~mL}$. Low volume syringe are time consuming compared to large volume but problem with large-volume is it is hard to take power on pressure and unfavourable incidence might occur. Thus, to enhance safety and control low volume syringe ( 1 to $5 \mathrm{~mL}$ ) should be used.(11)

\section{(ii) Instrumentation Using Master Apical File or Gutta Percha}

This are used for agitation while irrigation to improve its efficacy.(11)In straight root canal, filing with last file used during biomechanical preparation along with irrigating solution might enhance medicament withdrawal when checked with irrigating solution itself. While in curved roots rotary nickel titanium file found to be effective without altering root canal anatomy.(12,13)

According to Mridusmita Mukherjee et al in coronal third PUI method and that of master apical file performed better than the other group. In middle third efficacy was better for PUI, followed by NaviTip FX, master apical file, canal brush, in apical third PUI outperformed other groups.

\section{MACHINE ASSISTED}

It comprises of

(i) Rotary Brush- canal brush, endo brush, NaviTip FX.

(ii) Pressure Alternation Device- EndoVac, RinsEndo

(iii) Sonic irrigation- EndoActivator, Vibringe (iv) Passive ultrasonic irrigation (v) Laser. 


\section{(i) Rotary Brush}

Brushes do not actually render irrigating solution for removal of medicament. This act like auxiliaries during removal of medicament from canal or for increase movement of irrigating solution. 30-gauge needle encircled by brush (NaviTip FX) is commercially available in 17- and $25-\mathrm{mm}$ length. It has shown positive result in coronal cleaning of canal over the brushless needle. Although friction between brushes and canal irregularities may cause breakage of nonradio opaque bristles in canal which clinicians fail to identify, even by use of magnification. In early 1990s, same findings showing enhanced canal debridement by utilization of canal brushes by Keir et al.(14) The Endo brush is a spiral brush that comprises of nylon bristles set in twisted wires with handle. Used in active brushing and rotary motion but endo brush cannot be used till apex of canal due to its structure, that may cause clogging of debris in bottom region in the canal post use of it. Canal Brush is also an endodontic micro brush. It is highly flexible and is formed completely by polypropylene, works manually by rotary motion. Weise et al., said debris was efficiently withdrawn from canal extensions, irregularities by usage of Canal Brush with an irrigant. $(14,15)$

\section{(ii) EndoVac}

Is based on apical negative pressure irrigation to carry out efficient flow of irrigant and simultaneous removal respectively. Thus, improved penetration of irrigant in root complexity. Comprises of various sizes of cannula. Cannula is attached with high speed suction which produce negative pressure which draws irrigating solution towards end of cannula and removes irrigation solution along with debris from little openings.(16) Negative pressure produced causes risk free delivery of irrigating fluids till apex of root. Unit consist of master delivery tip. Macrocannula for removal of debris, intracanal medicament from upper and middle one third of root and microcannula for removal from apical one third. Advantages of EndoVac over other system is mainly safe delivery of irrigant without risk of apical extrusion, enhanced canal cleaning ability especially in apical one third because it inhibit vapor lock effect.(16)Procedure- Irrigate canal firstly by $5 \mathrm{~mL} 3 \% \mathrm{NaOCl}$ for half minute by macrocannula keeping it 3-4 $\mathrm{mm}$ short of working length, then microcannula positioned to entire $\mathrm{WL}$, followed by irrigation like macrocannula.(14)

RinsEndo- Introduced by Durr Dental Co. This irrigation system is also based on pressure alteration technology like EndoVac. Consist of handpiece, cannula which have sevenmillimeter-long exit aperture, and a syringe to deliver irrigating solution. $65 \mathrm{ul}$ of irrigating solution moves at frequency of $1.6 \mathrm{Hertz}$, with speed of $6.2 \mathrm{~mL} / \mathrm{min}$.(14)

According to Melek akman et.al Needle irrigation was least efficient, at apical and middle part. PUI, SAF, EndoVac, EndoActivator group withdraw significantly more than needle irrigation. ${ }^{(14)}$

\section{(iii) Endo Activator}

Sonic instruments in endodontics first described by Tronstad et al 1985. This sonically driven system compromised of cordless handpiece and plastic tips of various colour corresponding to file size yellow, red, blue. Tip is noncutting, made of medical-grade polymer, elastic enough and are 22 $\mathrm{mm}$ in length with marking rings at XVIII, XIX, XX mm.(17) Criteria for tip selection is select a tip which do not adhere to canal wall at apical 2-3 $\mathrm{mm}$ so that it enable easy up and down motion of tip.(18) Tips cannot be reused. Autoclaving the tip decreases its flexibility, thus reduces its back-and-forth action. Sonic system has been engineered for risk free triggering of irrigating solution safely and vigorously create hydrodynamic phenomenon. It is more competent to clean and remove medicament and efficiently enables cleaning of accessory canals.(19) Sonic activation system differ from ultrasonic as sonic system function at a low frequency (1-6 $\mathrm{kHz}$ ). Vibrating tip cause irrigant activation, produces intracanal waves. waves breakdown, which causes production of bubbles that oscillates in irrigant. Bubbles spread out, gets unsteady because of heat and pressure, then breakdown and explode. Each explosion produces thirty thousand shockwaves that infiltrate strongly, breakdown biofilms, and clean the surface.(20)Procedure - $10 \mathrm{~mL}$ of $3 \%$ $\mathrm{NaOCl}$ is irrigated using syringe and activated via handpiece with suitable tip short of $2 \mathrm{~mm}$ of apex, moving tip back and forth, that is II - III mm up down strokes at least up to sixty seconds. (14)

Vibringe- Is other type of sonic activation system discovered by Dutch company Vibringe B, which tie-up battery-driven vibrations $(9000 \mathrm{rpm})$ that adds sonic vibration to manual irrigation of canal. It consists of cordless handpiece which engages $\mathrm{X}$ mL leur lock syringe to which any needle can be attached and conventional syringe irrigation like delivery occurs, studies yet to found on MedLine.(14)

\section{(iv) Passive Ultrasonic Irrigation}

Introduced by Richman in 1957 in endodontics. Ultrasonically activated file has ability to prepare and simultaneously remove debris and medicament present in the canal.(19) Oscillating frequency of file is $25-30 \mathrm{KHz}$. Ultrasonically activated file have a typical form of node, antinode throughout its entire length. Drawback of ultrasonic irrigation is uncontrolled cutting of dentin.(21) Basically ultrasonic irrigation is of 2 types-

a) Irrigation associated with cutting instrumentation

b) One without cutting instrumentation so called PUI

PUI was 1st explained by Weller et al (1980). "Passive" denote no cut down activity by ultrasonically triggered instrument. $(22,23)$

Principal - Transmission of acoustic energy from oscillating file to irrigating solution.(22)

Mechanism of action - Acoustic streaming and cavitation. ${ }^{(22)}$

Acoustic streaming means fast motion of irrigant in circular motion surrounding an oscillating file. Acoustic streaming occurs in root canal during PUI is called as microstreaming. Displacement amplitude is at peak at tip of file, causing directional flow to coronal part of root canal. When file is not able to vibrate easily in canal microstreaming will decrease in intensity, but it will not stop totally. When file contacts canal at antinode there will be more decrease for displacement amplitude rather than when node touch the 
canal. Microstreaming is not directly proportional to surface area of file coming in contact to canal.(22) Cavitation is minimal and is restricted upto tip of file, whereas effect of acoustic streaming is significant. ${ }^{(22)}$

Procedure - U file no 15 or 20 is placed in center of root canal as apical as possible then $10 \mathrm{~mL}$ of $\mathrm{NaOCl}$ will be agitated for 1 minute at power setting of 6 and scaler set on endomode.(14)

According to Michael Hulsmann et al PUI performed better than RinsEndo, EndoActivator, canal brush, and manual syringe irrigation in apical third.(19)

\section{(v) Laser}

Laser Activated Irrigation is more effective for Cleaning of Root Canal. Er: YAG is most commonly used laser in endodontics. Because of photoacoustic streaming effect which occur when light energy pulse in irrigant. Laser emit photons to create photoacoustic shockwave in canals, shockwave is targeted 3- dimensionally into irrigant and thus effectively clean the canal. Pulse energy, length, frequency, exposure duration, and location of the fiber tip affects efficiency of laser. High pulse energy, short pulse length, long exposure duration, close positioning of the fiber tip in canal, was effective for cleaning of canal. While, the shape and diameter of the fiber tip does not affect its efficiency.(24,25) According to Evvriklia lourti et.al Significant difference between laser and manual, PUI, EndoVac group in coronal middle part but not significant difference at apical part. According to Hakan Gokturk et.al PUI, Laser activated irrigation removed significantly more medicament than bevelled needle irrigation. Double side vented needle irrigation, canal brush, Vibringe.(25) According to Dongxia et. al PIPS, Ultrasonic group showed greater calcium hydroxide reduction in apical third than EndoActivator and needle irrigation group.

\section{IRRIGANTS}

Various irrigants have been utilized for removal of medicament like NaOCl, EDTA, citric acid, maleic acid, chitosan.(26) Combine use of $\mathrm{NaOCl}$ and 17\% EDTA is not efficient for complete removal of calcium hydroxide. Effectiveness of calcium chelators like $10 \%$ citric acid, $7 \%$ maleic acid, has been studied and suggest them to be greatly effective in withdrawal of $\mathrm{CaOH}_{2}$ from canals. $(27,28)$ Chitosan is an artificial polysaccharide made from deacetylation of chitin. Which attributes to biocompatibility, biodegradability, bioadhesion, nontoxicity. Its chelating efficiency is same like EDTA and citric acid, but least hazardous effects. Study shows that no chelating agents tested are able to entirely remove calcium hydroxide. Chelating action of chitosan on dentin is not properly documented. Two theories to express chelating action of it.

First, the bridge model states two or more amino groups of chitosan adhere to identical metal ion. Second, the pendant model states one amino group to adhere and metal ion link to amino group like a pendant. One of the above actions may be reason to chelation of calcium ions in dentin that leads to decrease of inorganic content through smear layer.(27)
Another study shows 20\% citric acid better then 17\% EDTA solution for removal of Metapex. This might be due to citric acid penetrability in silicone oil is better than EDTA.(7)Apart to it $0.2 \%$ chitosan proved to be effective from XVII \% Ethylene Diamine Tetra-Acetic Acid and 20\% citric acid solution for withdrawal of water-based and oil-based $\mathrm{Ca}(\mathrm{OH})_{2}$. This is in accordance to Nandini et al and Ballal et al.(25) Thus Combine use of ultrasonic agitation and chelator leads to comparatively cleaner canal irrespective of vehicle used. Calcium hydroxide mixed with distilled water are comparatively easy to remove than Oil-based.(29,30,31)

\section{CONCLUSIONS}

Use of irrigants and agitation by different mechanical devices leads to increase removal of intracanal medicaments and adequate cleaning of canal.

\section{REFERENCES}

[1] Evans MD, Baumgartner JC, Khemaleelakul SU, et al Efficacy of calcium hydroxide: chlorhexidine paste as an intracanal medication in bovine dentin. Journal of Endodontics 2003;29(5):338-9.

[2] Kriplani R, Thosar N, Baliga MS, et al. Comparative evaluation of antimicrobial efficacy of various root canal filling materials along with Aloevera used in primary teeth: a microbiological study. Journal of Clinical Pediatric Dentistry 2013;37(3):257-62.

[3] Mukherjee P, Patel A, Chandak M, et al. Minimally invasive endodontics a promising future concept: a review article. International Journal of Scientific Study 2017;5(1):245-51.

[4] Khubchandani M, Baliga MS, Rawlani SS, et al. Comparative evaluation of different obturation techniques in primary molars: an in vivo study. European Journal of General Dentistry 2017;6(1):42-7.

[5] Patni PM, Chandak M, Jain P, et al. Stereomicroscopic evaluation of sealing ability of four different root canal sealers-an in vitro study. Journal of Clinical and Diagnostic Research 2016;10(8):ZC37-ZC9.

[6] Deepak BS, Sherin JC, Goud MK. Removal of intracanal medicaments - a review. Unique Journal of Medical and Dental Sciences 2015;3(3).

[7] Arslan H, Akcay M, Capar ID, et al. Efficacy of needle irrigation, endoactivator and photon-initiated photoacoustic streaming technique on removal of double and triple antibiotic pastes. Journal of Endodontics 2014;40(9):1439-42.

[8] Ba-Hattab R, Aljamie MA, Aldreib H, et al. Calcium hydroxide in endodontics: an overview. Open J Stomatology 2016;6(12):274-89.

[9] Chandak MG, Modi RR, Rathi BJ, et al. In vitro comparative assessment of diffusion of ion from calcium hydroxide with three different phytomedicine pastes through dentin. World Journal of Dentistry 2018;9(5):366-71. 
[10] Jain A, Patidar N, Nigam N, et al. An in vitro study: evaluation of intracanal calcium hydroxide removal with different file systems. Indian Journal of Dental Sciences 2017;9(1):26-9.

[11] Lee SJ, Wu MK, Wesselink PR. The effectiveness of syringe irrigation and ultrasonics to remove debris from simulated irregularities within prepared root canal walls. International Endodontic Journal 2004;37(10):672-8.

[12] Kuga MC, Tanomaru-Filho M, Faria G, et al. Calcium hydroxide intracanal dressing removal with different rotary instruments and irrigating solutions: a scanning electron microscopy study. Brazilian Dental Journal 2010;21(4):310-4.

[13] Pérez-Heredia M, Ferrer-Luque CM, González-Rodríguez MP. The effectiveness of different acid irrigating solutions in root canal cleaning after hand and rotary instrumentation. J Endod 2006;32(10):993-7.

[14] Pasricha SK, Makkar S, Gupta P. Pressure alteration techniques in endodontics-a review of literature. Journal of Clinical and Diagnostic Research 2015;9(3):ZE01ZE06.

[15] Jain P, Nilker V, Mandke L. An in vitro evaluation of calcium hydroxide medication removal using various irrigants and methods. SRM Journal of Research in Dental Sciences 2015;6(1):17-21.

[16] Ahamed AA, Raj JD. Negative pressure irrigation system: a review. Journal of Pharmacy Research 2019;13(1):814.

[17] Ruddle CJ. Endodontic disinfection: the sonic advantage. Dentistry Today 2017;36(6):84, 86-7.

[18] Gupta R, Sharma H, Kumari RA, et al. Effectiveness of two techniques in removal of calcium hydroxide medicament from root canals: an in-vitro assessment. Journal of Clinical \& Diagnostic Research 2018;12(7):ZC53-ZC5.

[19] Pabel AK, Hülsmann M. Comparison of different techniques for removal of calcium hydroxide from straight root canals: an in vitro study. Odontology 2017;105(4):453-9.

[20] Klyn SL, Kirkpatrick TC, Rutledge RE. In vitro comparisons of debris removal of the endoactivator system, the $\mathrm{F}$ file, ultrasonic irrigation and $\mathrm{NaOCl}$ irrigation alone after hand-rotary instrumentation in human mandibular molars. J Endod 2010;36(8):1367-71.

[21] Li D, Jiang S, Yin X, et al. Efficacy of needle, ultrasonic and endoactivator irrigation and photon-induced photoacoustic streaming in removing calcium hydroxide from the main canal and isthmus: an in vitro microcomputed tomography and scanning electron microscopy study. Photomedicine and Laser Surgery 2015;33(6):330-7.
[22] Van der Sluis LW, Versluis M, Wu MK, et al. Passive ultrasonic irrigation of the root canal: a review of the literature. International Endodontic Journal 2007;40(6):415-26.

[23] Tasdemir T, Celik D, Er K, et al. Efficacy of several techniques for the removal of calcium hydroxide medicament from root canals. International Endodontic Journal 2011;44(6):505-9.

[24] Kourti E, Pantelidou O. Comparison of different agitation methods for the removal of calcium hydroxide from the root canal: scanning electron microscopy study. Journal of Conservative Dentistry 2017;20(6):439-44.

[25] Gokturk H, Ozkocak I, Buyukgebiz F, et al. Effectiveness of various irrigation protocols for the removal of calcium hydroxide from artificial standardized grooves. Journal of Applied Oral Science 2017;25(3):290-8.

[26] Bronnec F, Bouillaguet S, Machtou P. Ex vivo assessment of irrigant penetration and renewal during the final irrigation regimen. Int Endod J 2010;43(8):663-72.

[27] Raghu R, Pradeep G, Shetty A, et al. Retrievability of calcium hydroxide intracanal medicament with three calcium chelators, ethylenediaminetetraacetic acid, citric acid and chitosan from root canals: an in vitro cone beam computed tomography volumetric analysis. Journal of Conservative Dentistry 2017;20(1):25-9.

[28] Faria G, Kuga MC, Ruy AC, et al. The efficacy of the selfadjusting file and ProTaper for removal of calcium hydroxide from root canals. Journal of Applied Oral Science 2013;21(4):346-50.

[29] Prada I, Micó-Muñoz P, Giner-Lluesma T, et al. Update of the therapeutic planning of irrigation and intracanal medication in root canal treatment. A literature review. Journal of Clinical and Experimental Dentistry 2019;11(2):e185-e193.

[30] Khedmat S, Shokouhinejad N. Comparison of the efficacy of three chelating agents in smear layer removal. J Endod 2008;34(5):599-602.

[31] Ahmetoglu F, Keles A, Simsek N. Effectiveness of the severel irrigation techniques for removal of calcium hydroxide-based intracanal medication from an artificial standardized groove in the apical root canal. Marmara Dental Journal 2013;2:53-6. 